used it covertly or admitted to using it for reasons other than pain.

- $4 / 18$ had risk factors for addiction. 3 of these 4 patients showed 'concerning use'.

- 9/18 patients were discharged on buccal fentanyl; there was scope for improvement in the quality of discharge

instructions as to how the patient should use buccal fentanyl.

Conclusions $5 / 18$ patients $(28 \%)$ were felt to have 'concerning use' of buccal fentanyl. 3 of these had clear risk factors for addiction this that were identified on admission. Since the time of data collection, the manufacturers have produced a guide for healthcare professionals that includes standardised screening tests for assessing the risk for potential opioid abuse in patients with breakthrough pain. Routine use of these should be considered, with clear explanation of risks shared with all patients, but particularly those with pre-existing risk factors. Patients discharged on buccal fentanyl should be discussed with the GP and have a clear plan on the discharge letter as to the dose, frequency, and type of pain that this is to be used for, along with the rationale.

\section{SODIUM VALPROATE SUBCUTANEOUS INFUSION; A VALUABLE ADJUNCT IN THE MANAGEMENT OF NEUROPATHIC PAIN IN PALLIATIVE PATIENTS}

C Davis, HK Crispin, C Marshallsay, S Haig, S Pennell, A Jenks. University Hospital Southampton NHS Foundation Trust

\subsection{6/bmjspcare-2018-ASPabstracts. 131}

Introduction Sodium valproate continuous subcutaneous infusion (CSCI) may be underutilised in the multi-modal management of neuropathic pain especially for patients requiring parenteral pain management due to phase of illness or symptom severity. We present a case series of adult patients treated with a sodium valproate CSCI.

Method Prospective data collection; six consecutive clinical cases managed by the Hospital Specialist Palliative Care Team (HSPCT) during final quarter of 2017.

Sodium valproate was commenced at a dose of 200$600 \mathrm{mg} / 24$ hour, in conjunction with a separate opioid or midazolam CSCI. Doses were up-titrated individually to between $400 \mathrm{mg} / 24$ hour and $1500 \mathrm{mg} / 24$ hour (maximal increments of $300 \mathrm{mg} / 24$ hour).

Results 4/6 patients had metastatic cancer, one cervical myelopathy and one osteoradionecrosis of the base of his skull; all had clinical reasons to require parenteral treatment. 5 experienced clinically significant improved pain control within 48 hours; allodynia resolved in the two patients who experienced this, one of whom had residual severe nociceptive pain due to rapidly progressive disease. There was no initial benefit attained in the patient whose starting dose was $200 \mathrm{mg} /$ 24 hour, but a dose of $400 \mathrm{mg} / 24$ hour was beneficial. There were no complications attributable to this treatment. Only $2 / 6$ patients required an increase in opioid dose.

Conclusion Unlike most neuropathic pain agents, sodium valproate is available in a parenteral preparation. Other benefits include that it is non-sedating and relatively safe in patients with renal impairment although dose modification is recommended. Six patients with a neuropathic component to their pain treated with sodium valproate CSCI as part of a multimodal analgesic strategy achieved rapid, efficacious control of their neuropathic pain. Titration was achieved over the course of days, the treatment was well-tolerated. We have found a starting dose of $400 \mathrm{mg} / 24$ hour to offer clinically relevant improvement in pain control. This case series supports our impression that it is an opioid sparing intervention.

\section{Service development | Posters 105-151}

\section{PALLIATIVE CARE NEEDS OF ADULTS WITH NEUROMUSCULAR DISORDERS: A PILOT CLINIC}

Mike Macfarlane, Tracey Willis, Derek Willis. West Midlands Deanery, The Robert Jones and Agnes Hunt Orthopaedic Hospital, Severn Hospice

\subsection{6/bmjspcare-2018-ASPabstracts. 132}

Background Neuromuscular disorders (NMD) have traditionally been managed by paediatric services. As more patients with these conditions are now living into adulthood, however, it is unclear a) what the palliative care needs are for this new adult population and b) how palliative care services can meet these needs.

Methods A 12 month pilot clinic was run jointly by a palliative medicine consultant and members of the neuromuscular multidisciplinary team (MDT) from a regional NMD centre. The aim of the clinic was to assess a) the number of patients, b) diagnoses and c) symptom burden that required palliative care input.

Patients were recruited if the NMD MDT assessed that they had significant symptom burden or that their disease trajectory had changed.

Results 9 patients were recruited to the joint clinic which was conducted 4 times in the year. These patients had a range of neuromuscular conditions and a variety of symptoms. Pain was the most commonly encountered symptom and ranged from very mild to severe with a mean pain score at initial assessment of 3 out of 5 (moderate).

Conclusions Adult patients with a variety of neuromuscular disorders were identified as having an unmet palliative care need. A range of symptoms were identified, with moderate pain being the most common. Despite these patients' symptom burden they are seldom referred to palliative care services.

\section{ARE REFERRALS FOR NON-INVASIVE VENTILATIONS (NIV) IN PATIENTS WITH MOTOR NEURONE DISEASE (MND) PROCESSED IN A SHORT TIME?}

Thurkaa Shanmugalingam, Harriet Roebuck. Colchester Hospital University Foundation Trust (CHUFT)

10.1136/bmjspcare-2018-ASPabstracts. 133

Background Patients with MND are at risk of respiratory compromise due to chest wall weakness and require NIV. As prognosis is short this should be a rapid referral to respiratory services. We advise that time between referral and assessment should be aimed at $<6$ weeks.

Methods Neurorehabilitation team lead supplied the details of eight MND patients referred for NIV assessments to Colchester Hospital (CHUFT) within the last twelve months. The usual referral pathway is via Papworth Hospital Cambridge but these patients were either too unwell or had chosen not to travel to Cambridge for assessment. A review of the patient's paper notes, Order comms system, Electronic 
Discharge Summaries, Respiratory clinic letter database and the separate patient neurorehab notes was undertaken.

Results One patient has been managed by Basildon Hospital so excluded from the audit which focused on CHUFT services. Of the seven remaining patients, two have not been seen by respiratory services as yet and the reason is unclear. One patient was admitted to Colchester General Hospital with life threatening respiratory compromise two months after referral and started NIV therefore as an inpatient. The final four patients were seen at 13 days, 6 weeks and $(2 \mathrm{x}) 4$ months post referral.

Conclusion There is no standard best practice process for managing these referrals. The NICE quality standard does not advise the time by which these patients should be assessed by respiratory services post referral. The tests required also could be standardised. At present it is not clear whether they require an arterial blood gas or sleep study. It might also be possible to start NIV and assess symptomatic benefit without tests. Writing agreed local guidelines would therefore be beneficial. In light of the patients short prognosis with MND it might advisable to aim for review in $<6$ weeks.

\section{EMAIL ALERTS ALLOW MORE RAPID ASSESSMENT BY PALLIATIVE CARE SERVICE AND DECREASE LENGTH OF HOSPITAL STAY FOR THOSE DISCHARGED HOME}

Hannah Curtis, Rob Smith, Ruth England. Derby Teaching Hospitals NHS Foundation Trust

\subsection{6/bmjspcare-2018-ASPabstracts. 134}

Background The Hospital Palliative Care Team (HPCT) at Royal Derby Hospital identified a number of circumstances where previously known patients were readmitted, but not promptly re-referred, to HPCT. The average length of time between admission to hospital and referral to HPCT was 8 days. We believed earlier HPCT intervention might reduce length of stay.

Methods Through our electronic hospital database we attach an e-alert to a patient's clinical details which generates an email on each re-admission. HPCT apply e-alerts to the records of patients who have stated they would not want further hospital admissions or to those complex patients for whom we feel early involvement in future would be advantageous. We check the e-alert inbox daily and respond by telephoning the ward to ascertain whether HPCT input is required.

Results We report on data collected over 30 months relating to 627 unique patients with e-alerts. 213 patients had unplanned re-admissions to hospital. A total of 294 emails were received, on average 2.25 emails per week - which did not present an excessive new workload. HPCT response time to an e-alert averaged 0.6 days. For those patients whose preference was to be discharged, the use of an e-alert was associated with a reduced time in hospital of 7 days. When the patient died in hospital, the average length of stay was 15 days.

Conclusion Admit alerts allow HPCT to make a more prompt assessment of patients previously known to the service. For patients who go on to be discharged home, this is associated with a decreased length of hospital stay. We suggest this may improve patient experience.

\section{TELEHEALTH PILOT: DEVELOPMENT AND SETTING UP OF A TELEHEALTH SERVICE FOR PALLIATIVE CARE} PATIENTS

Emma Randall. Weldmar HospiceCare, Macmillan

10.1136/bmjspcare-2018-ASPabstracts. 135

Weldmar HospiceCare has growing numbers of patients being referred to the service who want to be supported in their own homes for as long as possible. Weldmar are working in partnership with Macmillan who are providing funding for an 18 month secondment post to set up and lead a Telehealth pilot. Therefore enhancing the service offered to Weldmar patients and giving clinicians another tool to support and monitor patients. Telehealth is already being used in the UK for patients with long term conditions such as COPD and Heart failure but there is limited numbers of palliative care patients using a Telehealth service. The pilot consists of a POD which has a protocol uploaded to it that has been written using recognised palliative care outcome measures these are the Barthel Index and the IPOS scoring system. Patients $\log$ on daily completing the pre-set questions this will monitor changes in symptoms and also level of need. The results are stored on the POD so clinicians visiting the home can access these or clinicians can access these remotely from their PC to review the data the patient has inputted. The PODS have the capability for video conferencing and allow clinicians to use this to discuss with patients the data they have inputted and also carry out assessments of patients face to face via Skype. Patients have embraced the pilot and use of the POD. They report the POD is quick and easy to use, they like that clinicians can monitor them remotely. Clinicians are adapting to having another tool to use to support patients and having access to a wealth of data about patients. Also having the ability to monitor changes in symptoms without being reliant on patients relaying to them how they have been over a set period of time.

\section{DEVELOPING AN ON-LINE TOOLKIT TO SUPPORT END OF LIFE CARE}

Ruth England, Phil Shreeve. Derby Teaching Hospitals NHS Foundation Trust, Treetops Hospice

\subsection{6/bmjspcare-2018-ASPabstracts.136}

Background When the Liverpool Care Pathway was removed, a range of materials and guidance required review; furthermore, revised practice needed a platform in order to be shared. We decided that our new approach to care might be supported by a novel on-line resource.

Methods A suite of tools that could be used by different providers across Derbyshire at different stages in a patient's end of life journey were collected together. Initially, these documents were held on a webpage hosted by a local community healthcare provider. An accompanying webpage contained details of upcoming educational events and contacts. In the first 6 months the pages were used regularly. However, feedback stated they were not easily accessible to all staff and were clumsy to use. Funding was obtained to build a more 'user friendly' resource. An improved platform (www. 